\title{
DEGRADATION OF PETROLEUM HYDROCARBONS WITH THERMOTOLERANT MICROORGANISMS
}

\author{
S.A. Aitkeldiyeva ${ }^{1}{ }^{*}$, E.R. Faizulina ${ }^{1}$, L.G. Tatarkina ${ }^{1}$, M.B. \\ Alimzhanova $^{1,2}$, S.T. Daugaliyeva ${ }^{1}$, O.N. Auezova ${ }^{1}$, A.V. Alimbetova ${ }^{1}$, G.A. \\ Spankulova $^{1}$ and A.K. Sadanov ${ }^{1}$ \\ ${ }^{1}$ Scientific Production Center of Microbiology and Virology, Almaty, Kazakhstan \\ ${ }^{2}$ Al-Farabi Kazakh National University, Almaty, Kazakhstan \\ *E-mail: sa.kz@list.ru
}

\begin{abstract}
In the oil-producing regions of Kazakhstan located in a climatic zone with the predominance of high temperatures, an acute problem of environmental pollution by oil hydrocarbons is noted. This work was aimed at studying the degradation of crude oil by thermotolerant oil-oxidizing strains of microorganisms isolated from the soil in Atyrau region. Oil-oxidizing microorganisms were isolated by the method of cumulative cultures. The destruction of oil was determined using the gravimetric method and gas chromatography with mass spectrometry. The identification of active strains was carried out by sequencing of the $16 \mathrm{~S}$ rRNA gene. The research results showed that P1-35-14 and P2$50-2$ cultures were active at $35^{\circ} \mathrm{C}$ and $50^{\circ} \mathrm{C}$, respectively, while $\mathrm{K}-3$ culture demonstrated high activity at both temperatures. All three strains were the most actively decomposed by n-alkanes of crude oil, such as Tridecane, Dodecane, n-Heptadecane, Pentadecane, Hexadecane, n-Heneicosane, and showed good destruction activity toward aromatic compounds m-Xylene and Naphtalene. According to the results of sequencing the 16S rRNA gene, they were allocated to Rhodococcus fascians K-3, Gordonia amicalis P1-35-14, and Brevibacillus borstelensis P2-50-2 types. These strains are considered to be promising for the biological products development for bioremediation of oil-contaminated soils in an arid climate.
\end{abstract}

Keywords: Crude Oil, Gas Chromatography, Oil-contaminated Soil, Oxidation, Arid Climate.

(C) RASĀYAN. All rights reserved

\section{INTRODUCTION}

One of the priority sectors of the Kazakhstan's economy is the oil industry. In recent years, oil production in Kazakhstan has grown more than three times and reached 80 million tons per year. ${ }^{1}$ This is because oil is an irreplaceable source of the petrochemical industry and is the raw material for obtaining such oil products as fuel, synthetic polymers, etc ${ }^{2,3}$. Kazakhstan occupies leading positions by the volumes of oil production among the CIS countries. The largest oil fields-Tengiz, Karashyganak, Uzen, Zhanazhol, Kumkol, and others - are geographically located in the climatic zone with predominant high temperatures in the summer, which reach $40-50^{\circ} \mathrm{C}$. The soil cover in oilproducing territories is represented by brackish soil and salt marshes with high salt content. ${ }^{4}$

Oil production, its transportation and processing are associated with significant emissions of environmentally harmful substances. Although significant scientific attention has been given to the processes of biological cleaning, the development of efficient technologies for bioremediation in situ for deactivation of oil-polluted soils remains a challenge for the areas with arid climate.

According to the report about emissions of toxic substances of the United States Environmental Protection Agency (EPA) $)^{5}$, petrochemical industry is one of the ten main sources of toxic chemicals in the environment. Pollution with oil hydrocarbons is one of the most serious global concerns due of their toxicity to the environment, including humans ${ }^{6}$. Today, the biotechnological method of cleaning the environment from oil and oil products based on the use of highly active destructor microorganisms that can use hydrocarbons from oil is widely used in the world practice. In the recent studies, bacteria of over 80 genera have been identified, which are capable of degrading oil 
hydrocarbons. ${ }^{7}$ Since hydrocarbon-oxidizing microorganisms are a permanent component of the soil and aquatic biocenoses, using their catabolic activity for cleaning contaminated natural substrates seems feasible. Indisputable advantages of this method are efficiency, cost efficiency, environmental safety, technological flexibility, and the absence of secondary pollution. ${ }^{8-11}$

In case of oil pollution, three groups of ecological factors interact closely: (1) complexity, polycomponent nature of oil composition; (2) heterogeneity of the composition and structure of any ecosystem; and (3) manifoldness and variability of external factors in which the ecosystem exists: temperature, pressure, humidity, state of the atmosphere, hydrosphere, etc.

Temperature is one of the key factors that influence the biodegradation of oil hydrocarbons, and their physical and chemical composition in particular. ${ }^{3,7,8,12}$ It increases the speed of growth and metabolism of microorganisms, gas solubility, soil matrix, and improves physical and chemical state of contaminants. ${ }^{13}$ Besides, increasing the temperature increases the solubility of hydrophobic pollutants, decreases their viscosity, and improves the diffusion and transfer of long-chain n-alkanes from the solid phase into the aqueous phase. ${ }^{14}$

One of the largest oil producing regions of the Caspian sea region is the Atyrau region. The main deposits of oil and gas fields are concentrated here. The climate is characterized by sharp seasonal and daily fluctuations in the temperature, high rate of water evaporation and, consequently, by salinity and low soil moisture. Due to the environment pollution problems in the oil producing regions, studying the activity of oil-oxidizing microorganisms at different temperatures is currently highly relevant in Kazakhstan.

This research studied the degradation of crude oil by thermotolerant oil-degrading strains of microorganisms from collections and those isolated from the soil in Atyrau region at different temperatures.

\section{Materials and Methods}

\section{Soil and Crude Oil Samples}

Oil-contaminated soil from the Atyrau region. The Atyrau region is dominated by salt marshes and brackish soil complexes. The samples were taken in aseptic conditions from the $0-30 \mathrm{~cm}$ layer several meters from oil wells. The samples were placed into sterile bags in sealed polyethylene containers. The soil samples were crushed and sieved through a $2 \mathrm{~mm}$ mesh sieve to get rid of plant residues, stones and other coarse inclusions, and stored at $4^{\circ} \mathrm{C}$ for further physicochemical and microbiological analyses.

Oil in the Zhanatalap field has the density of $814 \mathrm{~kg} / \mathrm{m}^{3}$, low sulfur content $0.17-0.38 \%$, and low paraffin content $0.31-1.01 \%$.

\section{The Composition of the Mineral Medium}

The composition of the mineral medium used for isolating thermotolerant oil-oxidizing microorganisms included the following ingredients $(\mathrm{g} / \mathrm{l})$ : $\mathrm{NH}_{4} \mathrm{NO}_{3}-1, \mathrm{KH}_{2} \mathrm{PO}_{4}-1, \mathrm{~K}_{2} \mathrm{HPO}_{4}-1$, $\mathrm{MgSO}_{4}-0.2, \mathrm{CaCl}_{2}-0,02, \mathrm{FeCl}_{3}-$ traces, $\mathrm{NaCl}-10$, and 11 of distilled water (Sigma, Germany). For isolation and storage of pure cultures, nutrient agar was used (Titan BioTech LTD, India). All components of the bacterial media were analytically pure. All nutrient media were sterilized at $121^{\circ} \mathrm{C}$ for $20 \mathrm{~min}$.

\section{Isolation and Selection of Active Thermotolerant Oil-oxidizing Microorganisms}

For selecting thermotolerant collection cultures, they were sown apart on slant nutrient agar and grown at temperatures $35^{\circ} \mathrm{C}$ and $50^{\circ} \mathrm{C}$. The growth of the cultures was assessed visually by their intensity.

New thermotolerant oil-oxidizing microorganisms were isolated by the method of cumulative cultures. For this purpose, $20 \mathrm{~g}$ of contaminated soil were introduced into the Erlenmeyer flasks containing $200 \mathrm{ml}$ of mineral medium, and $10 \mathrm{ml}$ of oil from the Zhanatalap field were added. The flasks were placed in thermostatic shakers (Climo-Shaker ISFI-X, Sweden) at $35^{\circ} \mathrm{C}$ and $50^{\circ} \mathrm{C} .14$ days later, the first subinoculation to a fresh medium with oil was made, then after the next 14 days, the second subinoculation was made. The oil-oxidizing microorganisms were isolated by seeding the culture fluid into Petri dishes with nutrient agar. The grown morphologically different colonies were checked for purity by depleting seeding and then were seeded out to slant nutrient agar. The ability of the studied bacterial strains to grow in a liquid mineral medium with oil was assessed. For this 
purpose, $5 \mathrm{ml}$ of a suspension of cells of each culture were added to the flasks with $100 \mathrm{ml}$ of the medium, and oil was added in the amount of $1 \%$ by volume of the medium. The flasks were incubated in thermostatic shakers at corresponding temperatures for seven days. Oil degradation was assessed visually by the changes of the oil stain and biomass accumulation. The choice of strains was based on their high ability to degrade crude oil in a liquid medium.

\section{Oil Degradation by Selected Strains of Thermotolerant Microorganisms}

For this purpose, $1 \%$ of oil was added to the flasks with $100 \mathrm{ml}$ of mineral medium, after which $5 \mathrm{ml}$ of the suspension of the studied cultures were added. Cultivation was performed in thermostatic shakers at $35^{\circ} \mathrm{C}$ and $50^{\circ} \mathrm{C}$ for 14 days. Quantitative consumption of oil was determined using the gravimetric method. ${ }^{15}$ For this purpose, at the end of cultivation period, for extracting oil residuals, 50 $\mathrm{ml}$ of chloroform were added to the flasks, well stirred, and transferred into separating funnels. The chloroform extract was poured into tared vials and evaporated naturally in a fume hood for $24 \mathrm{~h}$. The residue was weighed on analytical weigher Explorer (Ohaus, USA).

All experiments were repeated three times.

\section{Microbiological Oxidation of Oil Hydrocarbons}

The ability of the selected cultures of thermotolerant microorganisms to degrade oil hydrocarbons was studied in a liquid mineral medium. The cultures were grown on slant nutrient agar at corresponding temperatures $\left(35^{\circ} \mathrm{C}\right.$ and $\left.50^{\circ} \mathrm{C}\right)$. Cells were washed off from the agar with mineral medium into $500 \mathrm{ml}$ sterile vials. $5 \mathrm{ml}$ of cells suspension of each studied strain were added to the vials with $100 \mathrm{ml}$ of the medium. The optical density (OD) was 0.1 . After that, $0.1 \%$ of oil from the Zhanatalap field (Atyrau region) was added. All vials were tightly closed with Teflon stoppers to avoid escape of oil hydrocarbons. The vials were incubated in thermostatic shakers $(160 \mathrm{rpm})$ at appropriate temperatures. Samples were taken after 2, 68, 96, and 168 hours. Analysis of the degree of crude oil biodegradation was studied by the method of gas chromatography with mass spectrometry. The noninoculated reference flasks were considered reference for abiotic losses.

\section{Gas Chromatography with Mass Spectrometry}

The petroleum hydrocarbons were extracted twice from $100 \mathrm{ml}$ of the culture broth with petroleum of Zhanatalap by $20 \mathrm{ml}$ chloroform during $30 \mathrm{~min}$. Then, $1.5 \mathrm{ml}$ of the extract were taken into $2 \mathrm{ml}$ vials, sealed with caps with PTFE/silicone septa (Agilent, USA), and placed on the ALS autosampler tray for analysis using GC-MS.

The petroleum hydrocarbons concentrations were measured by a 7890 Gas Chromatograph coupled with mass spectrometer (Agilent, Santa Clara, USA). DB-5MS column $(30 \mathrm{~m} \times 0.25 \mathrm{~mm}, 0.25 \mu \mathrm{m}$ film thickness, J\&W Scientific Inc., Folsom, CA, USA) was utilized as stationary phase while helium ( $>99.995 \%$, Orenburg-Tehgas, Russia) was utilized as a mobile phase $(1.0 \mathrm{ml} / \mathrm{min})$. The volume injected was $1.0 \mu \mathrm{l}$ with a split ratio of $10: 1$. The oven temperature of the GC was initially set to 40 ${ }^{\circ} \mathrm{C}$ for $2 \mathrm{~min}$, and then increased to $250^{\circ} \mathrm{C}$ at the rate of $10^{\circ} \mathrm{C} / \mathrm{min}$. The temperatures of the injector and transfer line were set at 250 and $280^{\circ} \mathrm{C}$, respectively. MS detection was performed at $70 \mathrm{eV}$ with the scan mass range $\mathrm{m} / \mathrm{z} 34-550$.

To control the gas chromatography system for recording and processing the results and data, Agilent MSD ChemStation software (version 1701EA) was used. Processing data included determination of retention times, peak areas, and processing the spectral data obtained by mass spectrometric detector. To decrypt the received mass spectra, Wiley 7 th edition and NIST'02 library (the total number of the spectra in the library exceeds 550 thousand) were used.

\section{Identification of the Strains of Microorganisms Cultural and Morphological Characteristics}

Morphology of the cells was examined using an optical microscope (Premiere model MAX-200, China). The cultural and morphological properties of the strains of microorganisms were assessed by the growth in Petri dishes with nutrient agar ${ }^{16}$. The typical physiological and biochemical characteristics of the studied strains of microorganisms, including Gram staining, sporulation, activity of catalase, oxidase, anaerobic growth, hydrolysis of gelatin, the use of carbohydrates (glucose, sucrose, fructose, arabinose, xylose and mannitol, etc.) were analyzed in accordance with the Bergey's Manual of Determinative for Bacteriology ${ }^{17}$. 


\section{S rRNA Sequencing Analysis}

For identifying the strains of microorganisms, the genomic DNA was extracted from 1-2 day old cultures of bacteria using the kit for DNA purification PureLink Genomic DNA Kit according to the manufacturer's protocol (Invitrogen, Carlsbad, USA). DNA concentration in the samples was measured by fluorimeter Qubit ${ }^{\circledR} 2.0$ with Qubit $^{\mathrm{TM}}$ dsDNA HS Assay Kit (Life Technologies, Oregon, USA). The genetic marker was section of the 16S rRNA gene. For amplification of a segment of $16 \mathrm{~s}$ RNA gene, a reaction mixture was prepared: $12.5 \mu$ of Q5® Hot Start High-Fidelity $2 \mathrm{X}$ Master Mix (New England Biolabs Ins., USA); pair of universal primers: $8 \mathrm{~F}$ (5'AGAGTTTGATCCTGGCTCAG-3') and 806R (5'-GGACTACCAGGGTATCTAAT-3') ${ }^{18}$ by $1.2 \mu 1$ per $10 \mu \mathrm{M}$ of concentration; DNA matrix and water. The total volume of the reaction mixture was 25 $\mu 1$. The amplification mode consisted of the following cycles: $95^{\circ} \mathrm{C}$ for five minutes, after that: $95^{\circ} \mathrm{C}$ for 30 seconds, $55^{\circ} \mathrm{C}$ for 40 seconds, $72^{\circ} \mathrm{C}$ for 50 sec-30 cycles; and elongation at $72^{\circ} \mathrm{C}$ for 10 minutes.

Fragments of 16S rRNA bacteria gene were sequenced using the Big Dye Terminator v3.1 Cycle Sequencing Kit (Applied Biosystems, USA) according to the manufacturer's protocol (BigDye ${ }^{\circledR}$ Terminator v3.1 Cycle Sequencing Kit Protocol Applied Biosystems, USA), followed by separation of fragments in automated 3500 DNA Genetic Analyzer (Applide Biosystems, Hitachi, Tokyo, Japan).

The results of sequencing were processed in application SeqA (Applied Biosystems). The homologous nucleotide sequences of $16 \mathrm{~S}$ rRNA genes were searched for using the BLAST application (Basic Local Alignment Search Tool) in the Gene Bank international database of the USA National Center for Biotechnology Information (htpp://www.ncbi.nlm.nih.gov) ${ }^{19}$. The phylogenetic analysis was performed using MEGA 6 software ${ }^{20}$. The nucleotide sequences were aligned using the ClustalW algorithm. Phylogenetic neighbors were identified using the BLASTN Neighbor-Joining (NJ) method ${ }^{19}$.

\section{Statistical Analysis}

Statistical processing of the studies' results was performed according to the generally accepted criteria of variational statistical analysis with the calculation of mean values $(\mathrm{M})$, mean arithmetic error $(\mathrm{m})$ with the use of the Microsoft Excel 2010 software package. Statistical significance of the differences in the average values was assessed according to the standard methods ${ }^{21}$. Statistically significant were the differences with $\mathrm{p}<0.05$.

\section{RESULTS AND DISCUSSION \\ Selection of Active Collection Cultures of Oil-oxidizing Microorganisms Growing at $35^{\circ} \mathrm{C}$ and $5^{\circ} \mathrm{C}$}

For selecting active oil-oxidizing microorganisms, inventory of the laboratory collection of hydrocarbon-oxidizing microorganisms was performed. 75 pure collection cultures were screened by their ability to grow at elevated temperatures $\left(35^{\circ} \mathrm{C}, 50^{\circ} \mathrm{C}\right)$. The results of the study showed that 54 out of 75 studied cultures featured good growth at $35^{\circ} \mathrm{C}$. At $50^{\circ} \mathrm{C}$, good growth was observed only in seven cultures. In the next stage, the ability of the selected bacterial strains to grow in a liquid mineral medium with $1 \%$ of oil was assessed. Oil degradation was assessed visually by changes in the oil stain and biomass accumulation.

It was found that 23 cultures out of 54 grew well on the mineral medium at $35^{\circ} \mathrm{C}$. With that, oil film was not observed on the surface of the medium; oil was either converted into homogeneous emulsion, or remained in the form of fine particles. Significant growth of biomass was noted. At $50^{\circ} \mathrm{C}$, all studied strains grew in the presence of oil; two of them showed good growth, four showed moderate growth.

Thus, among the collection cultures of oil-oxidizing microorganisms isolated from oil-contaminated soils of various fields in Kazakhstan, the strains that grow at elevated temperatures were isolated. As a result of screening, 23 cultures that showed good growth in oil at $35^{\circ} \mathrm{C}$, and seven cultures that grew well at $50^{\circ} \mathrm{C}$ were selected.

\section{Isolation of Thermotolerant Oil-oxidizing Microorganisms From Oil-polluted Soil in Western} Kazakhstan and Selection of the Most Active Cultures Growing at $35^{\circ} \mathrm{C}$ and $50^{\circ} \mathrm{C}$

New thermotolerant oil-oxidizing microorganisms were isolated by the method of cumulative cultures. The total of 34 isolates were isolated from the initial accumulation cultures and two 
subsequent subinoculations at $35^{\circ} \mathrm{C}$, and 14 isolates at $50^{\circ} \mathrm{C}$. The isolated cultures were tested for their ability to grow in a liquid mineral medium in the presence of $1 \%$ of oil. Their growth was assessed visually by the changes in the oil stain and biomass accumulation. At $35^{\circ} \mathrm{C}$, good growth on oil was shown by 17 cultures, and at $50^{\circ} \mathrm{C}$ by 10 cultures.

Thus, from the collection and newly isolated cultures of thermotolerant microorganisms, 40 cultures that showed good growth at $35^{\circ} \mathrm{C}$, and 17 cultures that showed good growth at $50^{\circ} \mathrm{C}$ were selected for further studies.

\section{Studying the Ability of the Selected Strains of Thermotolerant Oil-oxidizing Microorganisms to Degrade Oil at Elevated Temperatures $\left(35^{\circ} \mathrm{C}, 50^{\circ} \mathrm{C}\right)$}

Studying the quantitative consumption of oil hydrocarbons by the selected collection cultures using the gravimetric method showed that at $35^{\circ} \mathrm{C}$, oil destruction over 14 days was $23.7-70.5 \%$ (Fig.-1A).

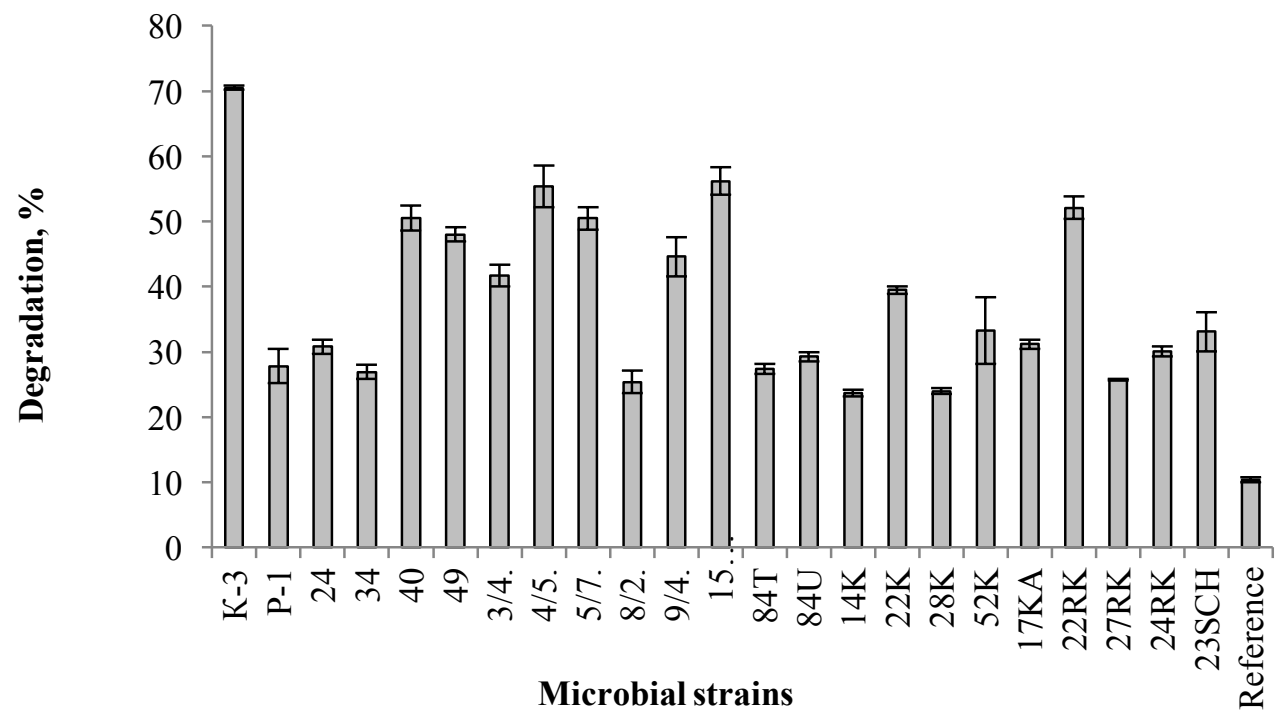

A

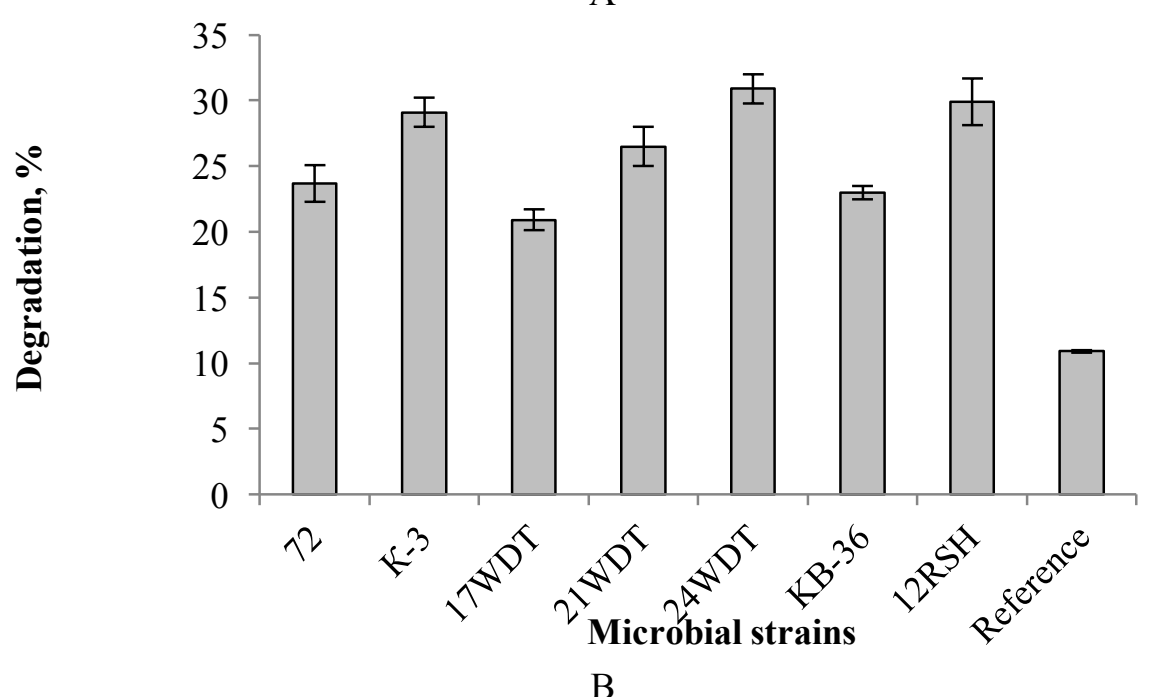

Fig.-1: Oil Degradation by Collection Strains of Oil-oxidizing Microorganisms at $35^{\circ} \mathrm{C}(\mathrm{A})$ and $50^{\circ} \mathrm{C}$ (B)

The most active was K-3 strain, which decomposed $70.5 \%$ of oil. Five strains consumed more than $50 \%$ of oil, four strains $39.5-48 \%$. The degrading activity of the other strains was much lower. The natural loss of oil was $10.4 \%$. With increasing the temperature, the activity of the cultures reduced. For instance, at $50^{\circ} \mathrm{C}$, oil degradation was $20.9-30.9 \%$ (Fig.-1B). In the reference, the loss was $10.9 \%$.

Studying the ability of isolated thermotolerant cultures of oil-oxidizing microorganisms to decompose oil at $35^{\circ} \mathrm{C}$ (Fig.-2A) showed that in a liquid mineral medium with oil, the degree of destruction was $18.7-52.0 \%$. Oil decomposition by most cultures did not exceed $28 \%$. The most active were P1-3514 and P2-35-9 cultures. With their growth, the oil destruction exceeded $50 \%$. 
At $50^{\circ} \mathrm{C}$, oil destruction for IP-50-3/1, P2-50-5, and P2-50-2 cultures was $29.4-33.8 \%$ (Fig.-2B). Abiotic oil losses amounted to $10.8 \%$.

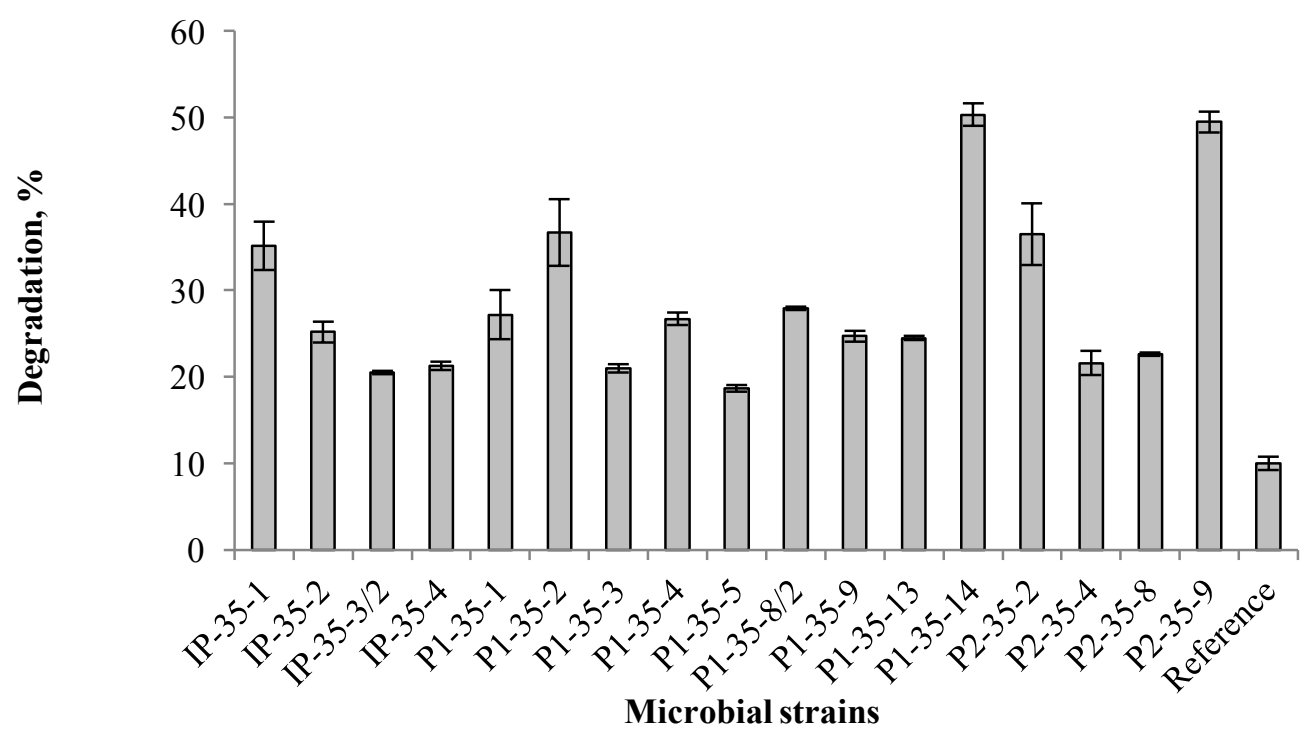

A

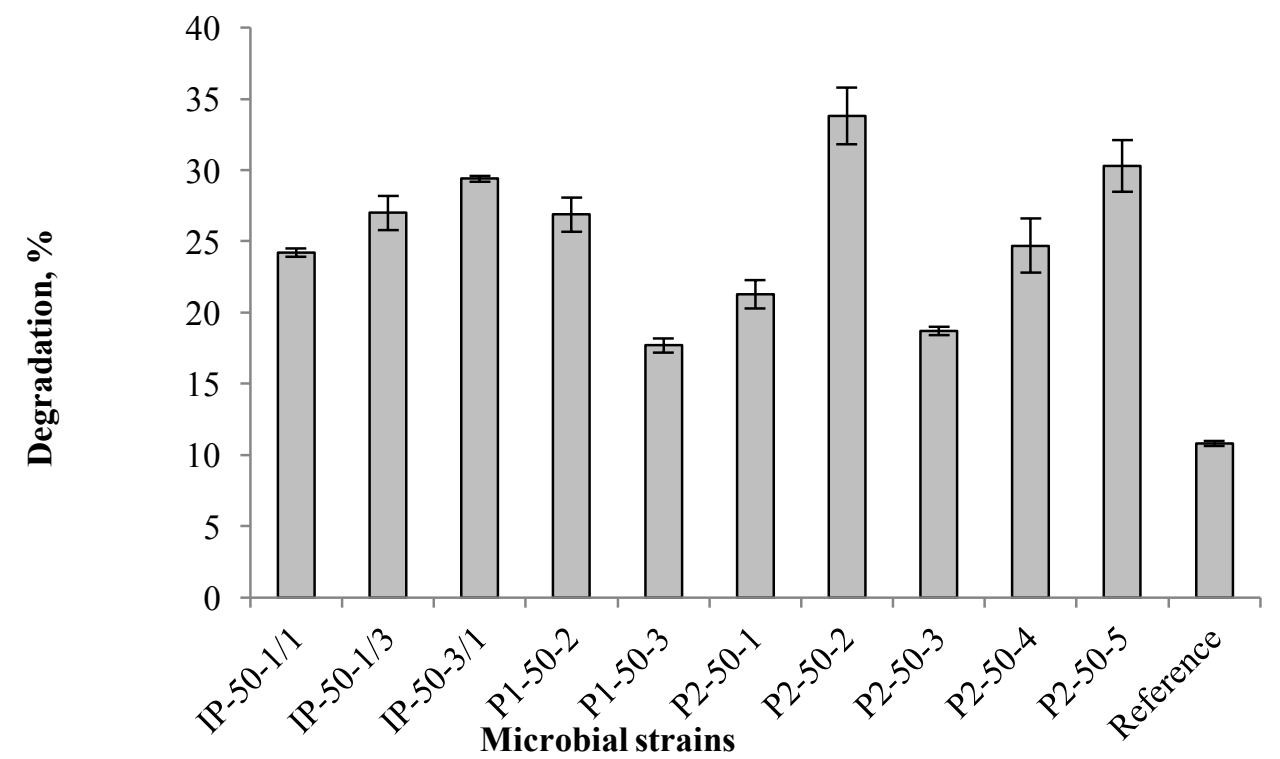

$\mathrm{B}$

Fig.-2: Oil Destruction by Thermotolerant Cultures of Oil-oxidizing Microorganisms at $35^{\circ} \mathrm{C}(\mathrm{A})$ and $50^{\circ} \mathrm{C}$

Thus, the study of oil degradation by the selected collection cultures showed that the most active was $\mathrm{K}-3$ strain, which decomposed more than $70 \%$ of oil at $35^{\circ} \mathrm{C}$, and $30.9 \%$ at $50^{\circ} \mathrm{C}$, and from the newly isolated strains - P1-35-14 and P2-50-2. These three strains were selected for further studies.

\section{Degradation of Petroleum Hydrocarbons of Crude Oil}

Degradation of oil hydrocarbons by selected strains of thermotolerant oil-oxidizing microorganisms was studied. The obtained data show that these processes proceed intensively both at $35^{\circ} \mathrm{C}$ and $50^{\circ} \mathrm{C}$. The most sensitive to degradation by the strains of thermotolerant microorganisms were n-alkanes, since it is known that aliphatic compounds are more susceptible to biodegradation than aromatic ones, and the greater the number of the rings is, the more difficult biodegradation is. The research studies correlate with the studies of most authors and, in particular, Mohamed et al. ${ }^{22}$ and Varjani et al. ${ }^{23}$ For instance, according to Mohamed et al., oil compounds are placed in the following order: $n$-alkanes $>$ branched alkane chains $>$ branched alkenes $>$ monoaromatic $>$ cycloalkanes $>$ polyaromatic $>$ asphaltenes. 
The results of analyzing gas chromatography with electron capture detection revealed different degrees of crude oil biodegradation at these temperatures. All three strains actively degraded nalkanes in crude oil, such as 1.7-Methyltridecane $\left(\mathrm{C}_{14} \mathrm{H}_{30}\right)$, Dodecane, 2,6,10-trimethyl-Pharnesan $\left(\mathrm{C}_{15} \mathrm{~N}_{32}\right)$, n-Heptadecane $\left(\mathrm{C}_{17} \mathrm{H}_{36}\right)$, Pentadecane, 2,6,10,14-tetramethyl-Norphitan $\left(\mathrm{With}_{19} \mathrm{H}_{40}\right)$, Hexadecane, 2,6,10,14-tetramethyl-Phitan $\left(\mathrm{C}_{20} \mathrm{H}_{42}\right)$ and n-Heneicosane $\left(\mathrm{C}_{21} \mathrm{H}_{44}\right)$.

At $35^{\circ} \mathrm{C}$, almost all above mentioned alkanes $(90 \%)$ were subjected to degradation by $\mathrm{K}-3$ strain as early as within 24 hours, their residual content ranged from $9.8 \%$ (Heptadecane) to $12.6 \%$ (Farnesan). After 168 hours, all n-alkanes were virtually decomposed. There were less that $5 \%$ of them left, except for Pentadecane, which amounted to $6.1 \%$ (Fig.-3).

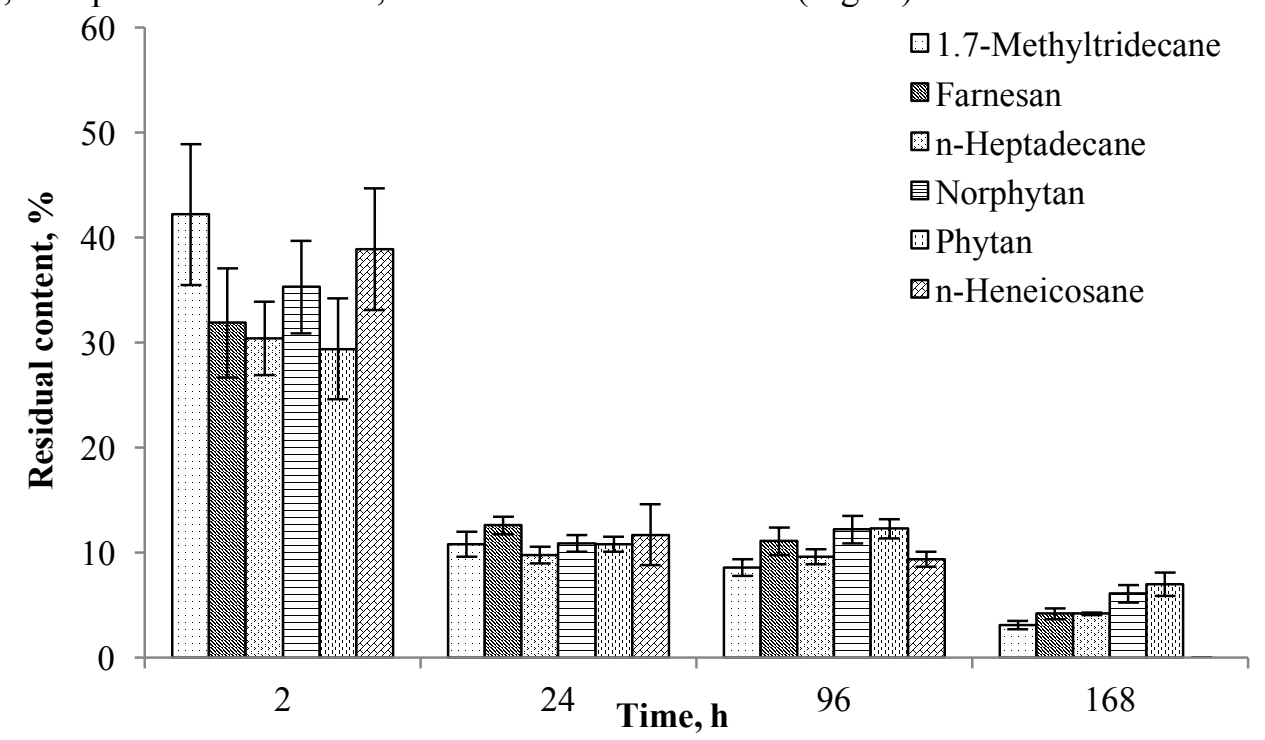

Fig.-3: Degradation of Oil Hydrocarbons at $35^{\circ} \mathrm{C}$ by K-3 Strain

For assessing the extent of aromatic compounds biodegradation, m-Xylene and Naphtalene were selected. After two hours of the experiment with K-3 strain at $35^{\circ} \mathrm{C}$, their amount was $24.3 \%$ and $27.7 \%$ (Fig.-4A). That is, more than $70 \%$ of these compounds were degraded, and by day 7 , more than $90 \%$ were degraded.
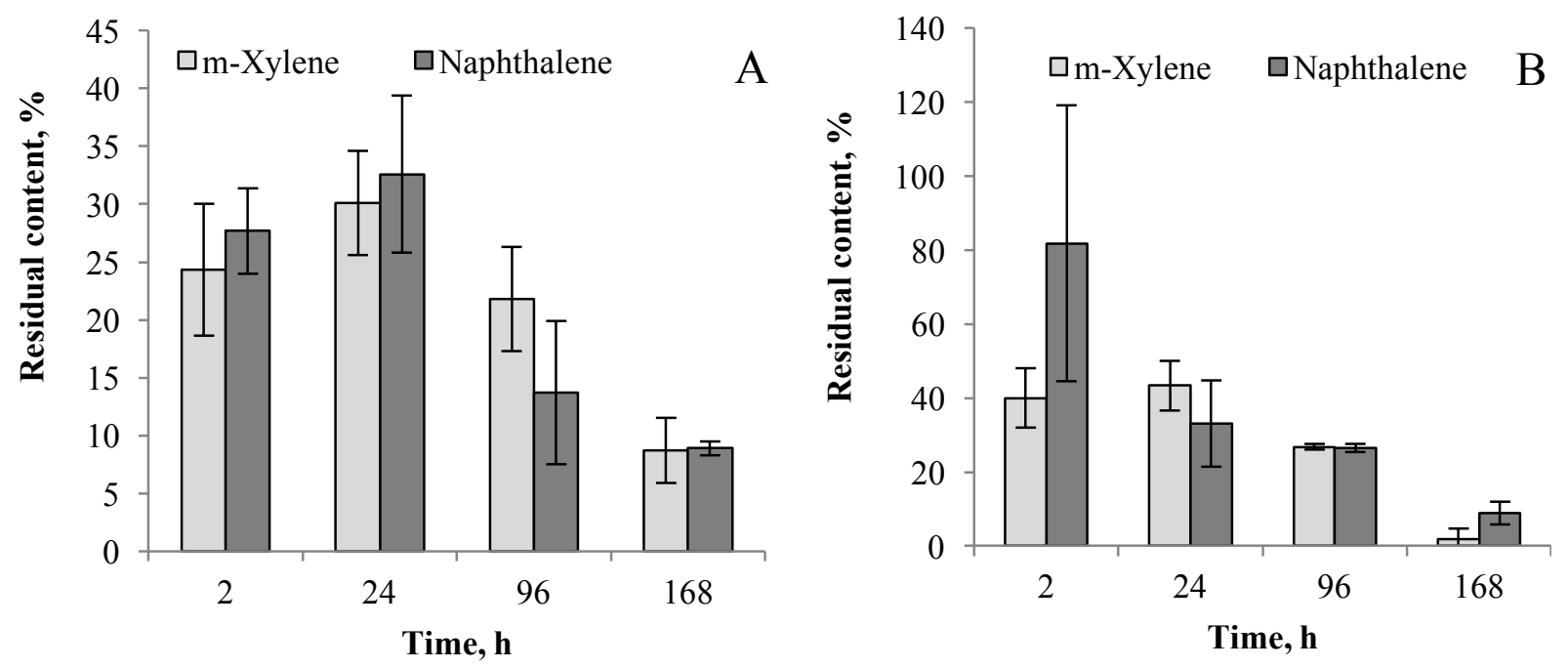

Fig.-4: Degradation of m-Xylene and Naphthalene in Oil at $35^{\circ} \mathrm{C}$ by K-3 Strain (A), and by P1-35-14 Strain (B) At $50^{\circ} \mathrm{C}$ (K-3 strain), after 24 hours, the concentration of n-alkanes decreased by half, compared to the first hours of incubation, and after 168 hours, less than $15 \%$ remained in the medium (Fig.-5). Naphthalene degradation at the same temperature was gradual, and after 168 hours, almost complete degradation of this compound occurred. The same pattern was observed with m-Xylene (Fig.-6A). 


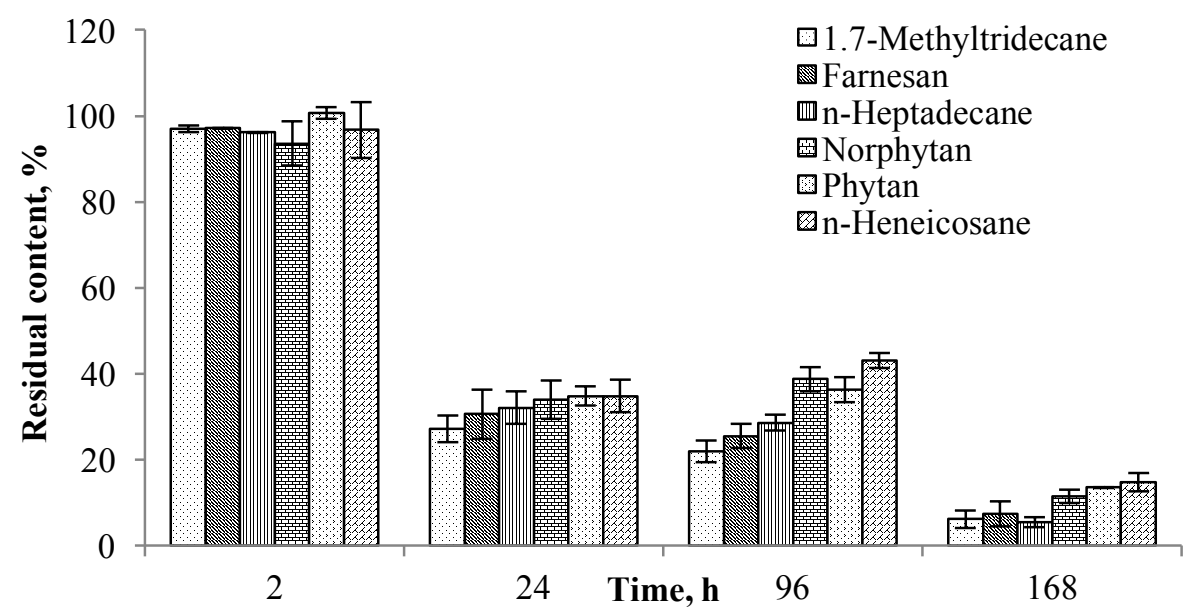

Fig.-5: Degradation of Oil Hydrocarbons at $50^{\circ} \mathrm{C}$ by K-3 Strain
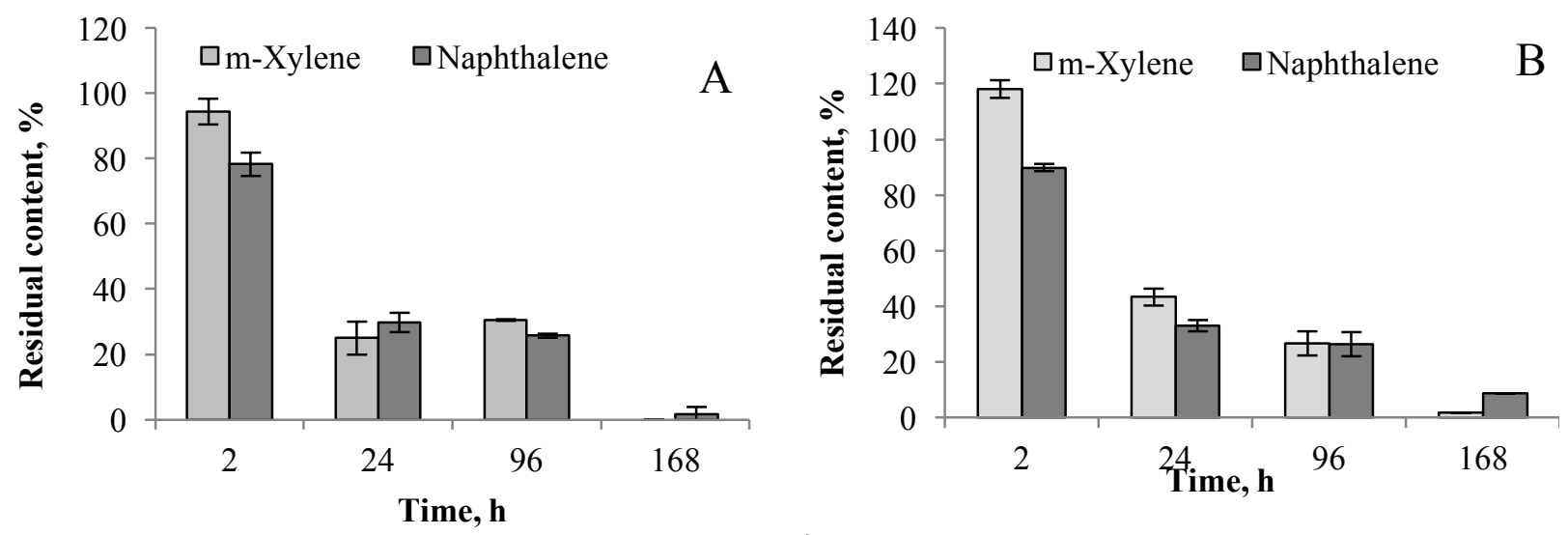

Fig.-6: Degradation of Oil Hydrocarbons at $50^{\circ} \mathrm{C}$ by K-3 Strain (A) and P2-50-2 Strain

The results of studying biodegradation of petroleum hydrocarbons by P1-35-14 strain showed that at $35^{\circ} \mathrm{C}$, after 96 hours, Methyltridecan, Farnesan and Heptadecane had been completely decomposed (Fig.-7), and after 168 hours, more than $90 \%$ of m-Xylene and Naphthalene had been decomposed (Fig.-4B).

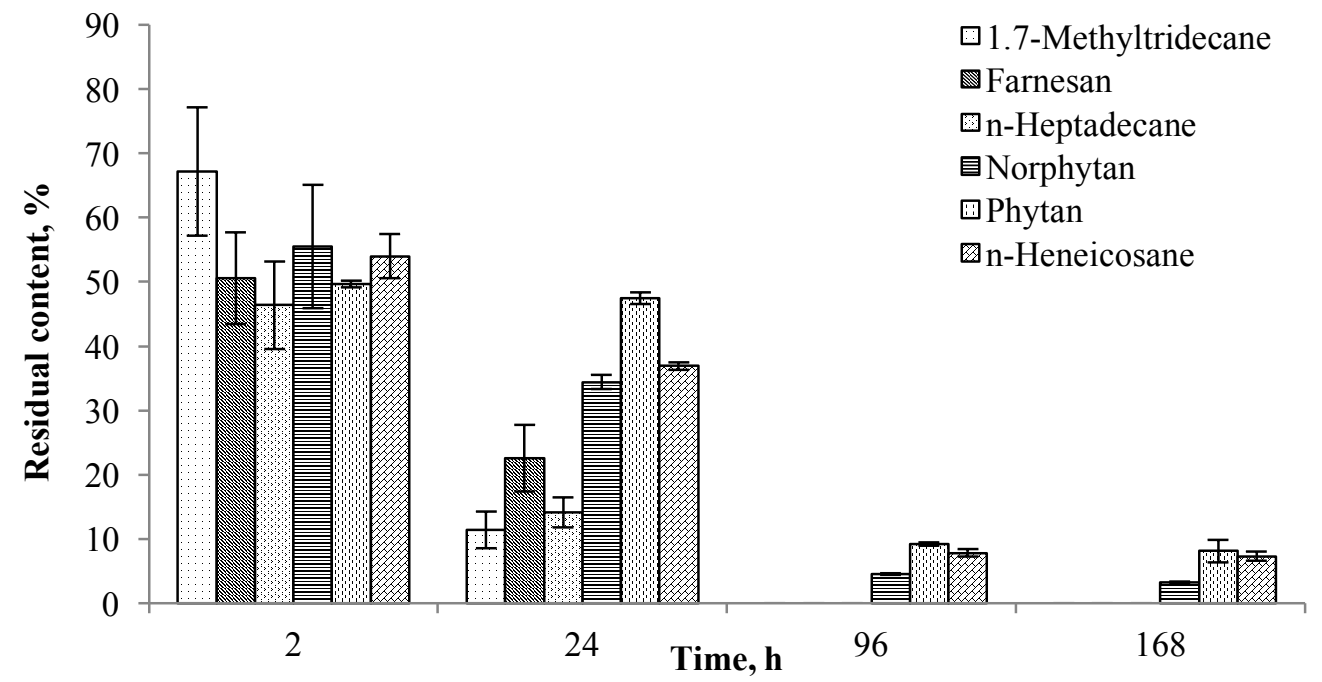

Fig.-7: Degradation of Oil Hydrocarbons at $35^{\circ} \mathrm{C}$ by P1-35-14 Strain

It was shown that at $50^{\circ} \mathrm{C}$ under the influence of P2-50-2 strain, the amount of n-alkanes after 24 hours had decreased by half, and after 168 hours, their residual amount was 11-26\% (Fig.-8), while more than $90 \%$ of m-Xylene and Naphthalene had been degraded in this time by the same strain (Fig.$6 \mathrm{~B})$. 


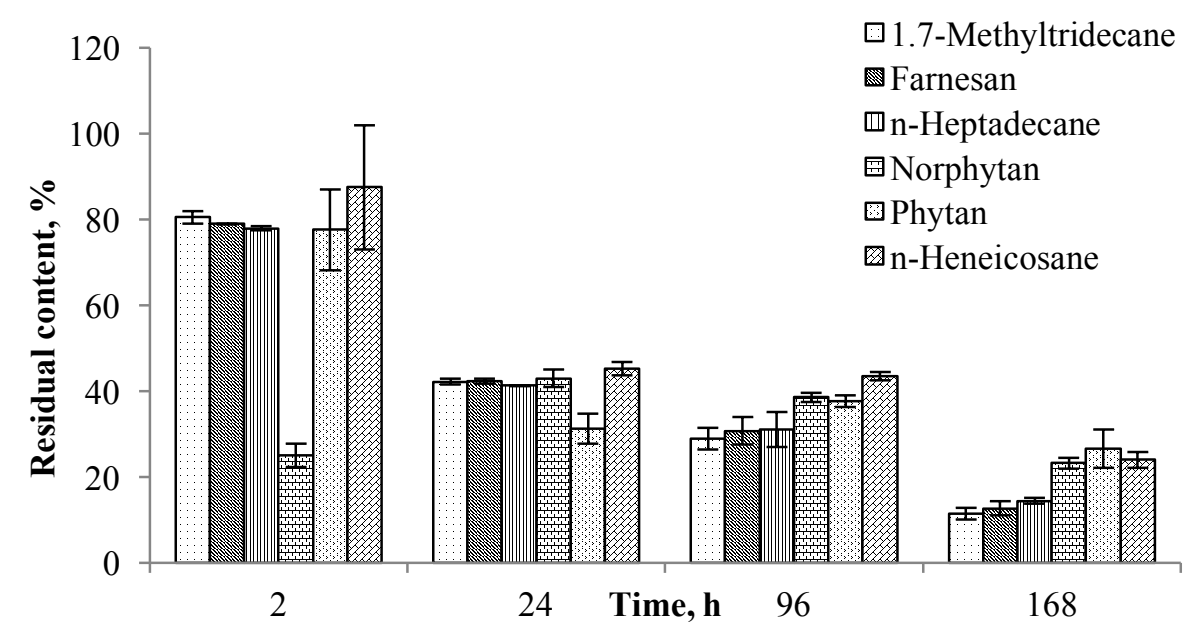

Fig.-8: Degradation of Oil Hydrocarbons at $50^{\circ} \mathrm{C}$ by P2-50-2 Strain

Thus, the obtained data showed that increasing the temperature to $50^{\circ} \mathrm{C}$ affected the degradation rate of $n$-alkanes and aromatic hydrocarbons in crude oil by the isolated thermotolerant strains. Comparison of the ability of two strains $\mathrm{K}-3$ and P2-50-2 to degrade n-alkanes and aromatic hydrocarbons at $50^{\circ} \mathrm{C}$ showed that K-3 strain was more active. While during cultivation of K-3 strain, the residual content of $\mathrm{m}$-Xylene and Naphthalene at $35^{\circ} \mathrm{C}$ after 168 hours was $8.7 \%$ and $8.9 \%$, at $50^{\circ} \mathrm{C}$, complete degradation of $\mathrm{m}$-Xylene occurred, and the content of Naphthalene in the medium was $1.6 \%$. This correlates with the studies of L. Boqun et al..$^{24}$, in which it was shown that thermotolerant Bacillus licheniformis strain was able to degrade oil at the temperatures from $35^{\circ} \mathrm{C}$ to $55^{\circ} \mathrm{C}$, and the decomposition rate increased with increasing the temperature, though slightly. For instance, analysis of gas chromatography with electron capture detection showed that the rate of degradation of oil hydrocarbons $\mathrm{C}_{25}-\mathrm{C}_{40}$, which were difficult to decompose, improved at $55^{\circ} \mathrm{C}$.

On the contrary, in the article of I. A. Delehan, it was shown that increasing the temperature not always had a positive effect on oil hydrocarbons oxidation. For instance, assessment of the degree of oil destruction by thermotolerant representatives of Gordonia and Rhodococcus genera in a liquid mineral medium with oil at elevated temperature $\left(45^{\circ} \mathrm{C}\right)$ showed that the strains were able to decompose $20-25 \%$ of oil in 14 days, with the initial oil concentration of $2 \%$. With that, the degree of oil degradation by these strains decreased almost twice with increasing the temperature of the medium. The process of oil destruction was performed most actively by Gordonia sp. 1D (55\% and $25 \%$ at $24^{\circ} \mathrm{C}$ and $45^{\circ} \mathrm{C}$, respectively), $R$. pyridinivorans L5A-BSU $(19 \%$ and $27 \%$ ) and Rhodococcus erythropolis Par7 (24\% and $20 \%$ ) strains ${ }^{25}$.

Most studies were devoted to biodegradation and bioremediation of oil hydrocarbons by consortia of microorganisms consisting of two or more strains of oil-oxidizing cultures of microorganisms. It is well known that this increases efficiency of biodegradation of oil and oil products ${ }^{26,27}$. More detailed study of the ability of the monocultures of the studied thermotolerant strains of microorganisms to degrade oil hydrocarbons will create consortia able to degrade oil hydrocarbons at elevated ambient temperatures and high soil salinity.

\section{Cultural and Morphological Characteristics}

The study of cultural and morphological characteristics of the selected strains of thermotolerant microorganisms showed that they all belonged to the aerobic gram-positive catalase-positive rods. They can grow in a wide range of temperatures from 5 to $55^{\circ} \mathrm{C}$; the optimum is $28-37^{\circ} \mathrm{C}$. At $1-$ $10 \%$ of $\mathrm{NaCl}$, good growth of all three cultures of microorganisms was observed. They do not hydrolyze starch.

$\mathrm{K} 3$ strain is represented by pleiomorphic stationary rods with rounded ends. The colonies are brightorange, round, opaque, matte, convex, with smooth edges. It does not form $\mathrm{H}_{2} \mathrm{~S}$ and $\mathrm{NH}_{3}$, and does not recover nitrates. It assimilates sucrose, fructose, maltose and mannitol. When grown on glucose, it forms an acid, does alkalize a medium with lactose. P1-35-14 strain is represented by small stationary rods. The colonies are small - up to $3 \mathrm{~mm}$, red and brilliant. It does not form $\mathrm{NH}_{3}$, it forms $\mathrm{H}_{2} \mathrm{~S}$, and 
does not recover nitrates. When grown on glucose, it forms an acid, does alkalize a medium with sucrose. It does not assimilate lactose and mannitol.

P2-50-2 strain is represented by agile rods that form endospores. The colonies are colorless, slightly shiny with smooth edges, with the diameter of $3 \mathrm{~mm}$. It forms $\mathrm{NH}_{3}, \mathrm{H}_{2} \mathrm{~S}$, restores nitrates to nitrites. It does not assimilate glucose and sucrose. It alkalizes a medium with lactose and mannitol.

\section{Analysis of Nucleotide Sequences}

Analysis of nucleotide sequences of 16S rRNA gene (Fig.-9) showed that the studied strains belonged to Gordonia, Rhodococcus, and Brevibacillus genera. Similarity of P1-35-14 strain to the closest relative Gordonia amicalis strain IEGM NR 028735.1 is $100 \%$, which allows assigning it to this species. Also, based on comparison of $16 \mathrm{~S}$ rRNA gene, it was found that the closest strain to strain K3 was Rhodococcus fascians strain ATCC 12974 NR 119126.1 (degree of homology 99\%), and for strain P2-50-2 - Brevibacillus borstelensis strain NBRC 15714 (degree of homology $100 \%$ ), which also allowed assigning these strains to these species.

Thus, the results of phylogenetic analysis of 16S rRNA gene showed the taxonomic position of the thermotolerant strains used in the work.

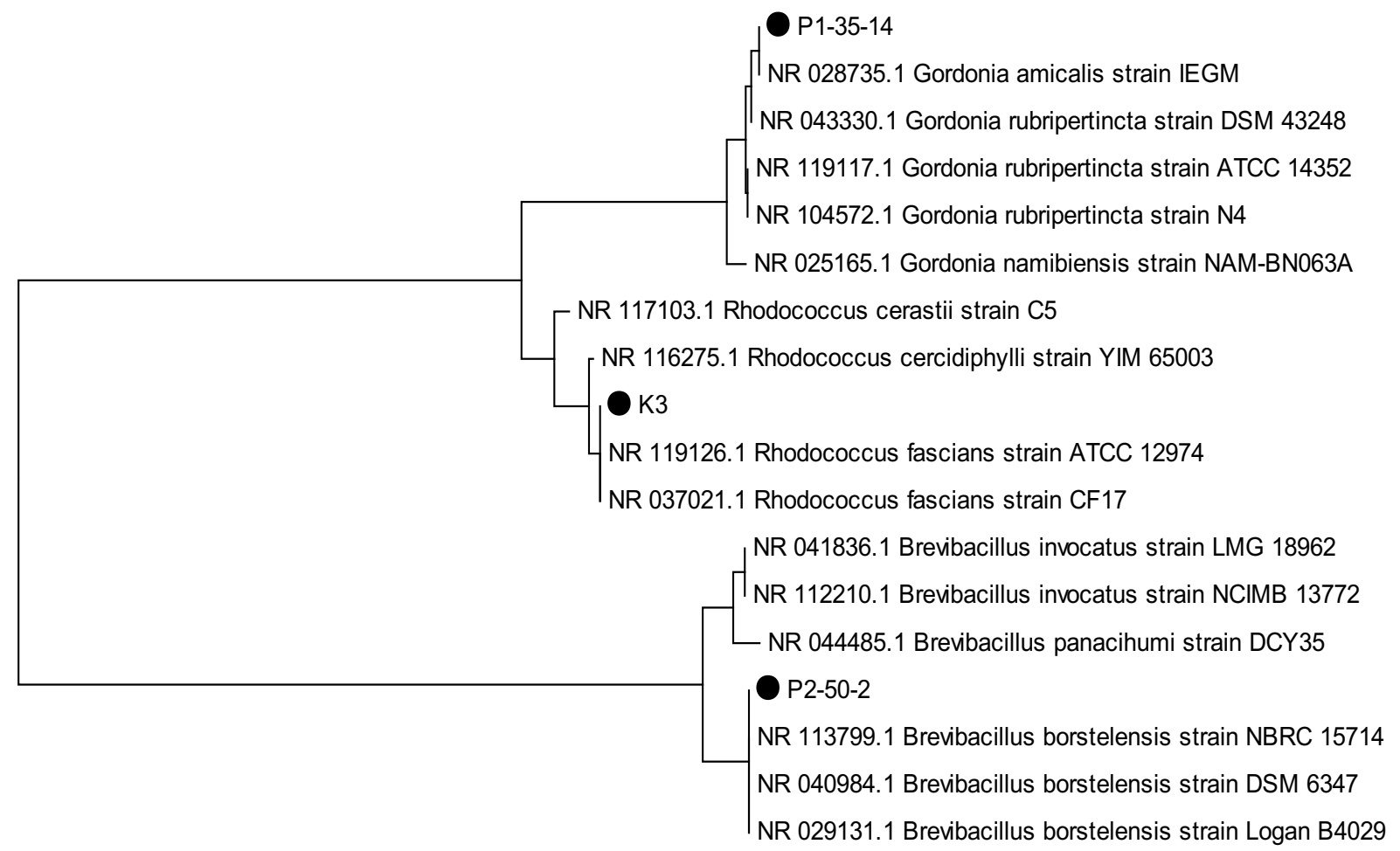

Fig.-9: The Dendrogram that shows the Phylogenetic Relationships of the Studied Strains with Relative Strains From the GenBank International Database

Microbial bioremediation is a widely used method of removing oil hydrocarbons, both in in-shore and aquatic ecosystems ${ }^{28}$. Simpler hydrocarbons of crude oil (alkanes and/or aromatic compounds) may be degraded by a wide spectrum of bacteria ${ }^{29-33}$, but the ability to degrade complex compounds (such as PAH, resins and asphaltenes) is only found in very few species ${ }^{34}$. Not all of them can degrade oil hydrocarbons in extreme environmental conditions, such as high temperatures and strong salinity. From this point of view, isolation and study of thermotolerant microorganisms are certainly relevant for the latitudes with sharply continental climate, where oil is actively produced.

Temperature and salinity are important environmental parameters that affect the process of oil compounds decomposition $^{35}$. Temperature has a huge effect on many aspects of the live activity of microorganisms, including oil-oxidizing ones. It changes the rate of chemical reactions in cells, and the state of cellular macromolecules. 
Specific climatic conditions of oil producing regions in the Republic of Kazakhstan remained the elective factor for a long time in the survival of native microorganisms with specific properties: the ability to withstand high $\left(50^{\circ} \mathrm{C}\right.$ on average) temperatures, salinity up to $7 \%$, and the lack of moisture in the soil. Bacteria with such properties can efficiently degrade oil in the areas with hot arid climate $^{36}$.

Most studies of the thermotolerant and/or thermophilic microorganisms are associated with the processes in petroleum reservoirs. Microorganisms that can withstand high pressure and fairly high critical temperatures are extracted. Their physiological properties and the biochemical ability to decompose hydrocarbons are studied ${ }^{37}$. Studies of the activity of thermotolerant microorganisms to use them for biodegradation and bioremediation of oil-contaminated soil in the areas with hot climate have not been paid sufficient attention to, and the diversity of thermotolerant bacteria, their metabolic ways of oil hydrocarbons degradation and transformation require further study.

\section{CONCLUSION}

Thus, the study has shown that isolated thermotolerant strains of oil-oxidizing microorganisms can degrade oil at elevated temperatures. All of them can oxidize n-alkanes and aromatic hydrocarbons of oil within 4-7 days, and the most of oxidizable oil fractions are degraded after $1-4$ days of the experiment. Comparison of the strains ability to degrade n-alkanes and aromatic hydrocarbons of oil showed an increase in the rate of oxidation of individual hydrocarbons with increasing the temperature. Further study of the ability of the studied cultures of thermotolerant microorganisms to degrade various concentrations and types of crude oil from various fields is envisaged. More detailed studies will allow creating in the future consortia on their basis, and to consider them as prospective destructors of oil and oil products in the contaminated soils in the conditions of the arid climate of Kazakhstan.

\section{ACKNOWLEDGMENT}

This study was supported and funded by the Ministry of Education and Science of the Republic of Kazakhstan (Grant no. APO5132128).

1. Business Information Center Kapital.kz. Available from: https://kapital.kz/economic/21860/neftegazovaya-otrasl-obespechivaet-25-vvp-rk.html

2. S. J. Varjani, Bioresource Technology, 223, 277(2017), DOI: 10.1016/j.biortech.2016.10.037

3. R. M. Atlas, Microbiology Reviews, 45(1), 180(1981).

4. M. D. Diarov, E. G. Gilazov, L. A. Demeeva, A. A. Bolshov, A. A. Zhmyhov, T. Z. Ergaliev and M. A. Durova, Ekologiya i neftegazovyi kompleks [Ecology and Oil and Gas Sector], Monograph in 5 volumes, Volume 2. Soil and vegetation cover, Volume 7. The ecological state of the Caspian region of the Republic of Kazakhstan and state programs on its rehabilitation, Galym, Almaty (2003).

5. United States Environmental Protection Agency. Available from: http://www.epa.gov/triexplorer/industry.htm

6. H. I. Abdel-Shafy and M. S. M. Mansour, Egyptian Journal of Petroleum, 25(1), 107(2016), DOI: $10.1016 / j$. .ejpe.2015.03.011

7. X. Xu, W. Liu, S. Tian, W. Wang, Q. Qi, P. Jiang, X. Gao, F. Li, H. Li and H. Yu, Frontiers in Microbiology, 9, 2885 (2018), DOI: 10.3389/fmicb.2018.02885

8. S. Chandra, R. Sharma, K. Singh and A. Sharma, Annals of Microbiology, 63, 417(2013), DOI: 10.1007/s13213-012-0543-3

9. M. Farhadian, C. Vachelard, D. Duchez and C. Larroche, Bioresourse Technology, 9, 5296(2008), DOI: $10.1016 /$ j.biortech.2007.10.025

10. F. Fernández-Luqueño, C. Valenzuela-Encinas, R. Marsch, C. Martínez-Suárez, E. VázquezNúñez and L. Dendooven, Environmental Sciense of Pollution Research, 18, 12(2011), DOI: 10.1007/s11356-010-0371-6

11. N. Das and P. Chandran, Microbial Degradation of Petroleum Hydrocarbon Contaminants: An Overview, Biotechnology Research International, 2011, 941810(2010), DOI: 10.4061/2011/941810

12. J. H. Leahy and R. Colwell, Microbial degradation of hydrocarbons in the environment, Microbiol. Rev., 54(3), 305(1990). 
13. M. Megharaj, B. Ramakrishnan, K. Venkateswarlu, N. Sethunathan and R. Naidu, Environment International, 37(8), 1362(2011), DOI: 10.1016/j.envint.2011.06.0030

14. J. Aislabie, D. Saul and J. Foght, Extremophiles, 10, 171(2006), DOI:10.1007/s00792-005-04984

15. Y. Y. Lurie, Analiticheskaya khimiya promyshlennykh stochnykh vod [Analytical chemistry of industrial wastewater], Chemistry, Moscow (1984).

16. F. Gerhardt, Metody obshchei bakteriologii [Methods of general bacteriology], Vol.3, Mir, Moscow (1984).

17. S. G. Holt, N. R. Kriey, P. H. A. Sneath, J. T. Staley and S. T. Williams, Bergy's Manual of Determinative for Bacteriology Williams and Wilkins, New York (1998).

18. E. Z .S. Vegas, B. Nieves, M. Araque, E. Velasco, J. Ruiz and J. Vila, Infection Control and Hospital Epidemiology, 27, 397(2006).

19. S. F. Altschul, T. L. Madden, A. A. Schäffer, J. Zhang, Z. Zhang, W. Miller and D. J. Lipman, Nucleic Acids Research, 25(17), 3389(1997).

20. S. Kumar, K. Tamura and M. Nei, Brieffings in Bioinformatics, 5(2), 150(2004).

21. S. Glants, Mediko-biologicheskaya statistika [Biomedical Statistics], Practika, Moscow (1998).

22. M. Mohamed, M. Al-Dousary, R. Hamzah and G. E. Fuchs, International Biodeterioration \& Biodegradation, 58, 213(2006), DOI: 10.1016/j.ibiod.2006.06.022

23. S. J. Varjani, D. P. Rana, A. K. Jain, S. Bateja and V. N. Upasani, International Biodeterioration \& Biodegradation, 103, 116(2015), DOI:10.1016/j.ibiod.2015.03.030

24. L. Boqun, J. Meiting, L. Jinpeng, W. Wentao and L. Xiaojing, Marine Pollution Bulletin, 106(12), 301(2016), DOI:10.1016/j.marpolbul.2015.09.053

25. I. A. Delegyan and A. E. Filonov, Fiziologicheskaya i taksonomicheskaya kharakteristika termotolerantnykh nefteokislyayushchikh bakterii roda Gordonia, vydelennykh iz proby grunta s territorii Moskovskogo neftepererabatyvayushchego zavoda (Kapotnya, g. Moskva) [Physiological and taxonomic characteristics of thermotolerant oil-oxidizing bacteria of genus Gordonia isolated from samples of the soil in the territory of the Moscow oil refining plant (Kapotnya, Moscow)], INR "Inter-Medical", IV, 45-48 (2014).

26. K. Sugiura, M. Ishihara, T. Shimauchi and S. Harayama, Environmental Science and Technology, 31(1), 45(1997), DOI:10.1021/es950961r

27. A. S. Roy, R. Baruah, M. Borah, A. K. Singh, H. P. D. Boruah, N. Saikia, M. Deka, N. Dutta and T. C. Bora, International Biodeterioration \& Biodegradation, 94, 79(2014), DOI: 10.1016/j.ibiod.2014.03.024

28. F. Abbasian, R. Lockington, M. Mallavarapu and R. Naidu, Applied Biochemistry and Biotechnology, 176(3), 1(2015).

29. K. S. M. Rahman, T. J. Rahman, Y. Kourkoutas, I. Petsas, R. Marchant and I. M. Banat, Bioresourse Technology, 90, 159(2003).

30. S. J. Varjani and V. N. Upasani, Bioresourse Technology, 222, 195(2016).

31. H. Wilkes, W. Buckel, B. T. Golding and R. Rabus, Journal of Molecular Microbiology and Biotechnology, 26, 138(2016).

32. G. M'rassi, F. Bensalah, J. Gury and R. Duran, Environmental Sciense and Pollution Research, 22, 15332(2015).

33. P. Arulazhagan, K. Al-Shekri, Q. Huda, J. J. Godon, J. M. Basahi and D. Jeyakumar, Extremophiles, 21, 163(2017).

34. S. Kumari, R. K. Regar and N. Manickam, Bioresource Technology, 254, 174(2018), DOI: 10.1016/j.biortech.2018.01.075

35. W. F. Röling, I. M. Head and S. R. Larter, Research Microbiology, 154(5), 321(2003), DOI: 10.1016/S0923-2508(03)00086-X

36. R. M. M. Abed, J. Al-Sabahi, F. Al-Maqrashi, A. Al-Habsi and M. Al-Hinai, International Biodeterioration \& Biodegradation, 89, 58(2014).

37. T. N. Nazina, N. M. Shestakova, A. A. Grigoryan, E. M. Mikhailova, T. P. Turova, A. B. Poltaraus, F. Csinsyan, N. S. Fangtian and S. Belyaev, Microbiology, 75(1), 70(2006).

[RJC-5580/2019] 